\title{
Evaluation of Effects of Cardiac Resynchronization on Coronary Blood Flow by Coronary Flow Reserve and in Patients with Idiopathic Dilated Cardiomyopathy: Does it Predict the Response?
}

\author{
Halil Akin, Ozcan Ozdemir'1, Önder Bilge², Onur Yildirim³ ${ }^{3}$ Rojhat Altindag² \\ Cardiology Clinics, Sinop Atatürk State Hospital, Sinop, ${ }^{1}$ Cardiology Clinics, Lokman Hekim University, ${ }^{3}$ Cardiology Clinics, Sincan State Hospital, Ankara, ${ }^{2}$ Department \\ of Cardiology, Gazi Yaşargil Training and Research Hospital, Diyarbakır, Turkey \\ ORCID: \\ Halil Akın: https://orcid.org/0000-0002-6651-7403 \\ Özcan Özdemir: https://orcid.org/0000-0001-8459-320X \\ Önder Bilge: https://orcid.org/0000-0001-8214-972X \\ Rojhat Altındağ: https://orcid.org/0000-0002-2479-9318 \\ Onur Yıldırım: https://orcid.org/0000-0002-9750-5413
}

\section{Abstract}

Background: The results of previous studies evaluating the effects of cardiac resynchronization therapy (CRT) on myocardial blood flow (MBF) and their relation with the response to CRT are conflicting. Materials and Methods: Sixty-one patients diagnosed with idiopathic dilated cardiomyopathy (IDC), a functional capacity (New York Heart Association [NYHA]) Class II or III, and left bundle branch block (LBBB) (QRS width $>150 \mathrm{~ms}$ ) were enrolled in the study. We aimed to evaluate the effects of CRT on MBF in patients with IDC and LBBB by coronary flow reserve (CFR) measurements and thereby tried to predict the responders. Results: Sixty-one patients with IDC were enrolled. CFR and hyperemic fractional flow reserve (FFR) increased after CRT. The only parameter affecting the increase in CFR was the change in FFR after CRT. Then, 44 patients who responded to the CRT treatment at 6 months were compared with 17 patients who did not. Left ventricle outflow tract time-velocity integral (LVOT-TVI), stroke volume (SV) and cardiac output index (COi) was detected significantly higher also left ventricular end-diastolic pressure (LVEDP) was lower in the CRT responders. However, there were no significant differences in coronary flow velocity measurements between the two groups. Moreover the regression analysis revealed that the baseline NYHA class, LVOT TVI, SV, COi, and LVEDP, which were changed due to increased blood flow after CRT implantation, is not associated with response to CRT. Conclusions: Our results suggest that MBF increased after CRT in patients with IDC probably by improving microvascular functions. However, the response to CRT treatment is not related to the changes in the coronary blood flow velocities after CRT.

Keywords: Cardiac resynchronization, coronary blood flow, idiopathic dilated cardiomyopathy

\section{INTRODUCTION}

Cardiac resynchronization therapy (CRT) has been accepted as a beneficial treatment strategy for a subgroup of patients with heart failure and an asynchronous contraction pattern. ${ }^{[1]}$ It has been shown that CRT improves hemodynamic function, ${ }^{[2]}$ heart failure symptoms, and exercise capacity; moreover, it

Received: 03-08-2020 Revised: 12-09-2020 Accepted: 17-09-2020

Published Online: 29-03-2021

\begin{tabular}{|l|l|}
\hline \multicolumn{2}{c|}{ Access this article online } \\
\hline Quick Response Code: & Website: \\
& http:/www.ijcva.com \\
& \\
& \\
\end{tabular}

reduces morbidity and mortality. ${ }^{[3]}$ It is suggested that CRT implantation in patients with left bundle branch block (LBBB) improves coronary blood flow by reducing left ventricular

Address for correspondence: Dr. Halil Akin Sinop Erfelek Yolu, 57000 0smaniye Köyü Tırkışlar Mevkii, Sinop, Turkey. E-mail: halilakin@yandex.com

This is an open access journal, and articles are distributed under the terms of the Creative Commons Attribution-NonCommercial-ShareAlike 4.0 License, which allows others to remix, tweak, and build upon the work non-commercially, as long as appropriate credit is given and the new creations are licensed under the identical terms.

For reprints contact: WKHLRPMedknow_reprints@wolterskluwer.com

How to cite this article: Akin $\mathrm{H}$, Ozdemir $\mathrm{O}$, Bilge Ö, Yildirim $\mathrm{O}$, Altindag R. Evaluation of effects of cardiac resynchronization on coronary blood flow by coronary flow reserve and in patients with İdiopathic dilated cardiomyopathy: Does it predict the response? Int J Cardiovasc Acad 2021;7:21-5. 
filling pressure, wall tension, and septal blood flow ${ }^{[4,5]}$. However, the results of previous studies evaluating the effects of CRT on myocardial blood flow (MBF) and their effects on the response to CRT are conflicting. In this study, we aimed to evaluate the effects of CRT on MBF in patients with idiopathic dilated cardiomyopathy (IDC) and LBBB by coronary flow reserve (CFR) measurements. Second, we tried to find the factors affecting the changes in CFR after CRT. Third, we searched any effects of the changes in coronary artery flow after CRT on the clinical outcomes and the therapeutic response.

\section{Materials and Methods}

Patients with a left ventricular ejection fraction (LVEF) $<35 \%$ and LBBB (QRS width $>150 \mathrm{~ms}$ ), diagnosed as IDC with functional capacity (New York Heart Association [NYHA]) Class II or III despite optimized medical treatment, who applied consecutively to our clinic were included in the study. All the patients who underwent coronary angiography and patients with coronary artery disease were excluded. Coronary flow velocity measurements were applied to the patients without coronary artery disease. Furthermore, patients with congenital and valvular heart disease, hypertrophic cardiomyopathy, chronic systemic disease or cor pulmonale, and atrial fibrillation were excluded. At the time of enrollment, all the patients were in a clinically stable condition on standard heart failure medication. Medication was kept constant during the study. Informed consent of each subject and the approval of the local ethics committee were obtained. The study protocol conforms to the Declaration of Helsinki (Rickham, 1964).

\section{Echocardiography}

Each patient underwent M-mode and two-dimensional (2D) echocardiography, followed by color flow imaging and pulsed- and continuous wave Doppler ultrasound. Transthoracic echocardiographic studies were performed using a commercially available ultrasound machine (iE33; Philips Medical Systems, Andover, MA) equipped with a $2.5-3.5-\mathrm{MHz}$ phased-array sector scan probe (S3). Left ventricle (LV) end-systolic volume, LVEF, left ventricular dimensions, left ventricle outflow tract time-velocity integral area (LVOT-TVI), and stroke volume (SV) were determined according to the recommendations of the American Society of Echocardiography. ${ }^{[6]}$ An index for cardiac output index (COi) was calculated from the $\mathrm{CW}$ aortic outflow spectrum: LV outflow tract diameter was measured from a 2D parasternal long-axis view. The measurements repeated after pacemaker implantation and optimization.

Biventricular pacemaker leads were inserted through the left subclavian vein, 1 in the atrial appendage, 1 in the right ventricular apex, and 3 in the coronary sinus $(90 \%$ in posterolateral vein). After pacemaker implantation, the atriobiventricular delay was optimized individually based on Doppler echocardiographic measurements. ${ }^{[7]}$

\section{Coronary flow velocity measurements}

A 0.014-inch, 15-Mhz Doppler guidewire was advanced through the catheter to the proximal portion of the left anterior descending (LAD) artery. Frequency analysis of the Doppler signals was carried out in real time by fast Fourier transform using a velocimeter. Once baseline flow-velocity data had been obtained, a bolus injection of intracoronary $18 \mathrm{mg}$ adenosine was given to obtain data during hyperemia. To confirm that maximal hyperemia had been achieved, coronary blood flow velocity was recorded during the administration of an additional larger dose of adenosine. This was repeated until a plateau in flow velocity was reached. Time-averaged peak coronary flow velocity (APV) was measured for each vessel. CFR was determined as the ratio of APV at maximal hyperemia (h-APV) to APV at baseline (b-APV) as described before. ${ }^{[6]}$ All measurements were made at a constant heart rate of 90 beats/min to exclude the influence of variant heart rate. This was accomplished by the dual chamber and biventricular pacing. Recordings were repeated $5 \mathrm{~min}$ after CRT. Afterward, a pressure guidewire was propagated through the LAD artery. Basal and hyperemic pressure measurements were performed at proximal $1 / 3$ and distal $1 / 3$ of the LAD artery. And, in this way, we determined a fractional flow reserve (FFR).

\section{Clinical evaluation of improved cardiac function}

Clinical improvement at 6 months was defined as reduction by $\geq 1$ functional class in the NYHA classification and an increase in the 6-min walk test by $\geq 20 \%$.

\section{Statistical analysis}

The numerical variables before and after CRT were compared using a paired $t$-test. The correlation between variables was tested by Pearson's correlation analysis. The independent factors affecting CFR after CRT was defined using linear logistic regression analysis. The numerical and continuous variables were compared Student's $t$-test and Mann-Whitney $U$-test between "responders" and "nonresponders." The factors affecting the response were evaluated by regression analysis.

\section{REsULTS}

Sixty-one patients (mean age: $57.8 \pm 12.3$ years), 24 females and 37 males with IDC, were enrolled in the study. The average LVEF was $26.9 \% \pm 7.5 \%$. The majority of the patients $(82 \%)$ have NYHA class III symptoms. COi, LVOT-TVI area, and SV increased and left ventricular end-diastolic pressure (LVEDP) decreased significantly after CRT. Time-b-APV before and after CRT was similar. However, time-h-APV increased remarkably after CRT. Due to this increased hyperemic coronary flow, CFR after CRT also increased. Basal FFR before and after CRT was similar. However, after adenosine injection, hyperemic FFR was found to be significantly higher after CRT compared to before [Table 1].

Correlation analysis revealed that CFR before and after CRT was not correlated with SV, COi, LVOT-TVI area, and systolic and diastolic blood pressures before and after CRT. However, the changes in CFR after CRT $(\triangle \mathrm{CFR})$ were correlated with the changes in LVEDP $(\triangle$ LVEDP $)(r=-0.4, P=0.03)$ and the changes in FFR $\left(\triangle \mathrm{FAR}_{\text {basal }} ; r=0.6, P=0.06\right.$ and $\Delta \mathrm{FAR}_{\text {adenosine }}$; $r=0.7, P=0.02)$. 
Linear logistic regression analysis revealed that the only parameter affecting the increase in CFR after CRT was the change in FFR after CRT [Table 2].

Then, 44 patients who responded to the CRT treatment at 6 months were compared with 17 patients who did not. Besides the baseline characteristics, early hemodynamic changes after CRT were also compared. Only the NYHA class was higher in the responder group regarding the baseline characteristics. LVOT-TVI, SV, and COi were significantly higher, and LVEDP was lower in the responders. However, there were no significant differences in coronary flow velocity measurements between the two groups [Table 3]. Moreover, the regression analysis revealed that the baseline NYHA class and the changes in LVOT-TVI, SV, COi, and LVEDP after CRT predicted the positive response to CRT treatment [Table 4].

\section{Discussion}

The main finding of our study (1) was an increase in both hyperemic CFR and FFR in the early period in cardiac resynchronization therapy. (2) The increase in FFR was detected as the only independent predictor of the increase in CFR after CRT implantation; The parameters predicting the response to CRT therapy are the increase in cardiac output and SV LVOT-TVI and decrease in LVEDP, but not changes in coronary flow rates.

Coronary blood flow in patients with IDC has been evaluated previously using different methods. The decrease in CFR in these patients; Vanderhayden et al. ${ }^{\left[{ }^{[8]}\right.}$ Santagata et al. ${ }^{[9]}$ Rigo et al. ${ }^{[10]}$ by echocardiography, Skalidis et al. ${ }^{[1]]}$ by intracoronary Doppler measurements has been demonstrated. In patients with IDC, MBF decreases, especially when a metabolic ${ }^{[2]}$ and pharmacologic vasodilator ${ }^{[13]}$ agent is used. Similar to our results, Skalidis et al.$^{[11]}$ showed that coronary blood flow is normal at rest but significantly reduced at maximal hyperemia, as well as the reduced CFR. These changes in MBF are first suggested to be caused by left ventricular hypertrophy and dilatation and/or increased end-diastolic pressures. ${ }^{[14]}$ However, later, structural and/or functional alterations of the small coronary vessels (microcirculation) have been implicated in pathogenesis. Capillaries offer the most resistance to coronary blood flow during hyperemia, ${ }^{[15]}$ and since IDC is associated with areas of interstitial and perivascular fibrosis causing loss of ceiling effects of capillaries to hyperemic blood flow, ${ }^{[16,17]}$ functional and/or structural changes in microcirculation in IDC may explain reduced coronary flow during hyperemia. Recently, Gulati et al. ${ }^{[18]}$ showed that patients with IDC exhibit microvascular dysfunction and the severity of which is associated with the degree of LV impairment. If microvascular dysfunction contributes to the pathogenesis of dilated cardiomyopathy (DCM), the underlying mechanism is more likely to involve stress-induced repetitive stunning rather than chronic myocardial hypoperfusion.

Accordantly, the abnormalities in endothelium-independent coronary flow regulation in conjunction with the abnormal

\begin{tabular}{|c|c|c|c|}
\hline & CRT (-) & CRT (+) & $P$ \\
\hline LVOT-TVI $(\mathrm{cm} / \mathrm{sn})$ & $19.9 \pm 2.2$ & $24.9 \pm 1.8$ & 1 \\
\hline $\mathrm{SV}\left(\mathrm{ml} / \mathrm{m}^{2}\right)$ & $32.8 \pm 8.4$ & $40.4 \pm 6.3$ & 0.001 \\
\hline COi (L/min) & $2.9 \pm 0.7$ & $3.7 \pm 0.6$ & 0.001 \\
\hline LVEDP (mmHg) & $15.6 \pm 4.8$ & $13.4 \pm 3.9$ & 0.01 \\
\hline $\mathrm{b}-\mathrm{APV}(\mathrm{cm} / \mathrm{sn})$ & $20.8 \pm 7.7$ & $21.7 \pm 6.8$ & 0.2 \\
\hline h-APV (cm/sn) & $37.2 \pm 11.6$ & $47.4 \pm 13.1$ & 0.001 \\
\hline CFR & $1.84 \pm 0.3$ & $2.3 \pm 0.6$ & 0.001 \\
\hline $\mathrm{FFR}_{\text {basal }}$ & $0.92 \pm 0.035$ & $0.92 \pm 0.032$ & 0.3 \\
\hline $\mathrm{FFR}_{\text {adenosine }}$ & $0.85 \pm 0.038$ & $0.9 \pm 0.03$ & 0.001 \\
\hline
\end{tabular}

LVOT-TVI: Left ventricle outflow tract- time velocity integral, SV: Stroke volume, b-APV: Time-averaged peak coronary flow velocity at baseline, h-APV: time-averaged peak coronary flow velocity at maximal hyperemia, CFR: Coronary flow reserve, FFR: Fractional flow reserve, COi: Cardiac output index, LVEDP: Left ventricle end-diastolic pressure, CRT: Cardiac resynchronization therapy

\begin{tabular}{|c|c|c|c|c|}
\hline Variable & $\beta$ & SE & $t$ & $P$ \\
\hline$\Delta$ LVOT-TVI & 0.03 & 0.4 & 0.7 & 0.5 \\
\hline$\Delta \mathrm{SV}$ & 0.004 & 0.005 & 0.8 & 0.4 \\
\hline$\Delta \mathrm{COi}$ & 0.02 & 0.03 & 0.5 & 0.2 \\
\hline$\triangle$ LVEDP & -0.03 & 0.3 & -0.2 & 0.1 \\
\hline$\Delta \mathrm{FFR}_{\text {basal }}$ & 4.6 & 2.4 & 1.9 & 0.08 \\
\hline$\Delta \mathrm{FFR}_{\text {adenosine }}$ & 9.6 & 4.0 & 2.4 & 0.04 \\
\hline \multicolumn{5}{|c|}{$\begin{array}{l}\text { CRT: Cardiac resynchronization therapy, } \triangle \text { LVOT-TVI: The changes } \\
\text { in left ventricle outflow tract- time velocity integral, } \Delta \text { SV: The } \\
\text { changes in stroke volume, } \Delta \text { COi: The changes in cardiac output index, } \\
\Delta \text { LVEDP: The changes in left ventricular end-diastolic pressure after } \\
\text { CRT, } \Delta \mathrm{FFR}_{\text {basal }} \text { : The changes in basal fractional flow reserve of a left } \\
\text { anterior descending artery, } \Delta \mathrm{FFR}_{\text {adenosine }} \text { : The changes in hyperemic } \\
\text { (after adenosine) fractional flow reserve after CRT, SE: Standard error }\end{array}$} \\
\hline
\end{tabular}

microvascular endothelial function are frequently observed in these patients. ${ }^{[19-21]}$ The clinical significance of this finding disclosed. Rigo et al. found that the decreased coronary blood flow during a vasodilator stimulation is a poor prognosis in the patients with IDCM ${ }^{[10]}$ and Santagata et al. ${ }^{[9]}$ showed that the decrease in CFR is associated with a worsening in the functional status of these patients. Endothelial dysfunction occurs in IDC patients, and also, there is a positive correlation with NHYA class in DCM. ${ }^{[22]}$ Patients with DCM and LBBB show more severe forms of microvascular dysfunction, which is related to worse left ventricular function and lack of contractile reserve. Ciampi et al. claimed that therapeutic interventions to restore microvascular function may improve left ventricular function parameters in patients with DCM. ${ }^{[5]}$ Moreover, coronary endothelial dysfunction is involved in myocardial fibrosis and worsening heart failure concomitant with DCM.

In previous studies, it was reported that there was no improvement in MBF after CRT, but improved myocardial 


\begin{tabular}{|c|c|c|c|}
\hline & $\begin{array}{l}\text { Nonresponders } \\
\quad(n=17)\end{array}$ & $\begin{array}{l}\text { Responders } \\
\quad(n=44)\end{array}$ & $P$ \\
\hline Age (years) & $58.3 \pm 13.8$ & $56.6 \pm 12.6$ & 0.3 \\
\hline Female (\%) & 42 & 38 & 0.2 \\
\hline HT (\%) & 82 & 80 & 0.4 \\
\hline DM (\%) & 24 & 21 & 0.3 \\
\hline $\mathrm{EF}(\%)$ & $25.8 \pm 6.3$ & $24.8 \pm 6.8$ & 0.3 \\
\hline \multicolumn{4}{|l|}{ NYHA class } \\
\hline II & 41 & 10 & 0.01 \\
\hline III & 59 & 90 & \\
\hline \multicolumn{4}{|l|}{ Medications (\%) } \\
\hline Furosemide & 82 & 80 & 0.6 \\
\hline Spironolactone & 76 & 72 & 0.4 \\
\hline Beta-blockers & 77 & 76 & 0.7 \\
\hline Digoxin & 35 & 32 & 0.4 \\
\hline ACE-I & 71 & 75 & 0.5 \\
\hline LVOT-TVI (cm/sn) & $21.2 \pm 0.8$ & $23.9 \pm 0.7$ & 0.01 \\
\hline $\mathrm{SV}\left(\mathrm{ml} / \mathrm{m}^{2}\right)$ & $36.8 \pm 5.4$ & $40.1 \pm 4.3$ & 0.001 \\
\hline COi (L/min) & $3.1 \pm 0.7$ & $3.6 \pm 0.6$ & 0.001 \\
\hline LVEDP (mmHg) & $15.4 \pm 2.8$ & $13.6 \pm 3.4$ & 0.01 \\
\hline b-APV (cm/sn) & $20.4 \pm 5.7$ & $21.5 \pm 4.9$ & 0.2 \\
\hline h-APV (cm/sn) & $45.2 \pm 10.6$ & $47.1 \pm 11.1$ & 0.1 \\
\hline CFR & $2.1 \pm 0.4$ & $2.2 \pm 0.5$ & 0.1 \\
\hline $\mathrm{FFR}_{\text {basal }}$ & $0.92 \pm 0.034$ & $0.92 \pm 0.033$ & 0.7 \\
\hline FFR $_{\text {adenosine }}$ & $0.89 \pm 0.03$ & $0.90 \pm 0.03$ & 0.1 \\
\hline
\end{tabular}

LVOT-TVI: Left ventricle outflow tract- time velocity integral, SV: Stroke volume, b-APV: Time-averaged peak coronary flow velocity at baseline, h-APV: time-averaged peak coronary flow velocity at maximal hyperemia, CFR: Coronary flow reserve, FFR: Fractional flow reserve, COi: Cardiac output index, LVEDP: Left ventricle end-diastolic pressure, CRT: Cardiac resynchronization therapy, EF: Ejection fraction, ACE-I: Angiotensinconverting enzyme-I, NYHA: New York Heart Association

\begin{tabular}{|c|c|c|c|c|}
\hline Variable & $\boldsymbol{\beta}$ & SE & $t$ & $P$ \\
\hline NYHA class & 1.1 & 1.4 & 0.7 & 0.02 \\
\hline$\Delta$ LVOT-TVI & 3.3 & 2.4 & 1.7 & 0.03 \\
\hline$\Delta \mathrm{SV}$ & 2.4 & 1.8 & 0.8 & 0.04 \\
\hline$\Delta \mathrm{COi}$ & 2.2 & 2.3 & 2.5 & 0.01 \\
\hline$\triangle$ LVEDP & -2.3 & 2.3 & -2.2 & 0.01 \\
\hline$\Delta \mathrm{FFR}_{\text {basal }}$ & 0.4 & 0.2 & 0.9 & 0.5 \\
\hline$\Delta \mathrm{FFR}_{\text {adenosine }}$ & 0.9 & 0.3 & 0.4 & 0.2 \\
\hline
\end{tabular}

NYHA: New York Heart Association, $\triangle$ LVOT-TVI: The changes in left ventricle outflow tract- time velocity integral, $\Delta \mathrm{SV}$ : The changes in stroke volume, $\triangle$ COi: The changes in cardiac output index, $\triangle$ LVEDP: The changes in left ventricular end-diastolic pressure after CRT, $\Delta \mathrm{FFR}_{\text {basal }}$ : The changes in basal fractional flow reserve of a left anterior descending artery, $\triangle \mathrm{FFR}_{\text {adenosine }}$ : The changes in hyperemic (after adenosine) fractional flow reserve after CRT, SE: Standard error

glucose metabolism or provided a more homogeneous blood flow. ${ }^{[23-26]}$ Knaapen et al ${ }^{[27]}$ showed that MBF does not change after CRT, but hyperemic MBF increases significantly by positron emission tomography. Similarly, Flevari et al. also demonstrated increased hyperemic MBF after CRT by transesophageal echocardiography. ${ }^{[28]}$ The septal blood flow is reduced in patients with $\mathrm{LBBB} .^{[5]}$ Thus, just the disappearance of LBBB by CRT may explain the improvement of MBF in these patients. Blanc et al. ${ }^{[29]}$ reported the normalization of left ventricular function after the disappearance of LBBB that may contribute to improved systolic functions after CRT. Knaapen et $a l{ }^{[27]}$ suggested that an increase in hyperemic MBF and CFR in the early period after CRT is related to the reduction in left ventricular filling pressures and wall stress. However, Flevari et al. ${ }^{[28]}$ found that hyperemic forearm blood flow is also increased after CRT which is widely used as an index of endothelial function. ${ }^{[30]}$ Similar to previous reports, ${ }^{[27,28]}$ we found that hyperemic blood flow increases after CRT by CFR measurement. We also found that the increase in FFR after hyperemia is the only parameter affecting the increase in CFR.

Kaźmierczak et al. showed that CFR increased significantly in LAD is a predictor for a clinical improvement after CRT. ${ }^{[31]}$ Valzania et al. stated that an increase in LAD flow is observed in CRT responders with IDC. They claimed that the increase in LAD flow is associated with an improvement in regional myocardial contraction and a decrease in intraventricular dyssynchrony. ${ }^{[30]}$ Yildirim et al. ${ }^{[32]}$ also showed that the increase in LAD flow velocities by successful CRT is concordant for improving the systolic and diastolic echocardiographic parameters, such as diastolic filling time, $\mathrm{dP} / \mathrm{dT}$, and ejection fraction $\%$. However, they said that the changes in the coronary blood flow velocities by CRT are not directly linked to the changes in conventional echocardiographic parameters. Moreover, 2 nonresponder patients in their study had no significant change in the coronary velocities after CRT. Similarly, our results also showed that the response to CRT was not associated with the changes in coronary blood flow velocities after CRT.

Primary outcome of this study was the improvement in coronary blood flow after CRT implantation and this improvement may likely because of the endothelial functions although cannot be proved. However, this improvement in coronary blood flow was not correlated with the response to CRT treatment in contrary to other previous reports. Although abnormal microvascular endothelial function is frequently observed in these patients, the efforts to improve endothelial functions may not effective in clinical outcomes. Future researches are needed to define how endothelial functions are affected by CRT treatment and their role in therapy.

\section{Conclusions}

Our results suggest that the main pathophysiologic mechanism affecting MBF in the microvascular dysfunction is the patients with IDC and cardiac resynchronization causes an increase in hyperemic MBF by improving microvascular functions. However, the response to CRT treatment is not related to the changes in the coronary blood flow velocities after CRT. 


\section{Study limitations}

The number of patients with DCM in the present study was relatively small, which was related to a complex invasive protocol of the study. We did not compare DCM patients with or without LBBB, as we intended to evaluate patients selected for CRT.

\section{Financial support and sponsorship \\ Nil.}

\section{Conflicts of interest}

There are no conflicts of interest.

\section{References}

1. Adam G, Eiran ZG, John R. Optimizing cardiac resynchronization therapy: An update on new insights and advancements. Curr Heart Fail Rep 2018;15:156-60.

2. Eoin RH, Jonathan MB, Andrew C, Simon C, Tom J, Manav S, et al. Improvement of right ventricular hemodynamics with left ventricular endocardial pacing during cardiac resynchronization therapy pacing. Clin Electrophysiol 2016;39:531-41.

3. Bradley DJ, Bradley EA, Baughman KL, Berger RD, Calkins H, Goodman SN, et al. Cardiac resynchronization and death from progressive heart failure: A meta-analysis of randomized controlled trials. JAMA 2003;289:730-40.

4. Kirk JA, Kass DA. Electromechanical dyssynchrony and resynchronization of the failing heart. Circ Res 2013;113:765-76.

5. Ciampi Q, Cortigiani L, Pratali L, Rigo F,Villari B, Picano E, et al. Left Bundle branch block negatively affects coronary flow velocity reserve and myocardial contractile reserve in nonischemic dilated cardiomyopathy. J Am Soc Echocardiogr 2016;29:112-8.

6. Galderisi M, Cosyns B, Edvardsen T, Cardim N, Delgado V, Di Salvo G, et al. Standardization of adult transthoracic echocardiography reporting in agreement with recent chamber quantification, diastolic function, and heart valve disease recommendations: An expert consensus document of the European Association of Cardiovascular Imaging. Eur Heart J Cardiovasc Imaging 2017;18:1301-10.

7. Wang J, Nie Z, Chen H, Shu X, Yang Z, Yao R, et al. Benefits of Cardiac Resynchronization Therapy in an Asynchronous Heart Failure Model Induced by Left Bundle Branch Ablation and Rapid Pacing. J Vis Exp 2017; (130):56439.doi: 10.3791/56439.

8. Vanderhayden M, Bartunek J, Verstreken S, Mortier L, Goethals M, de Bruyne B. Non-invasive assessment of coronary flow reserve in idiopathic dilated cardiomyopathy: Hemodynamic correlations. Eur J Echocardiography 2005;6:47-53.

9. Santagata P, Rigo F, Gherardi S, Pratali L, Drozdz J, Varga A, et al. Clinical and functional determinants of coronary flow reserve in non-ischemic dilated cardiomyopathy: An echocardiographic study. Int J Cardiol 2005; 105:46-52.

10. Rigo F, Gherardi S, Galderisi M, Pratali L, Cortigiani L, Sicari R, et al. The prognostic impact of coronary flow-reserve assessed by Doppler echocardiography in non-ischaemic dilated cardiomyopathy. Eur Heart J 2006;27:1319-23.

11. Skalidis EI, Parthenakis FI, Patrianakos AP, Hamilos MI, Vardas PE. Regional coronary flow and contractile reserve in patients with idiopathic dilated cardiomyopathy. J Am Coll Cardiol 2004;44:2027-32.

12. Neglia D, Parodi O, Gallopin M, Sambuceti G, Giorgetti A, Pratali L, et al. Myocardial blood flow response to pacing tachycardia and to dipyridamole infusion in patients with dilated cardiomyopathy without overt heart failure. A quantitative assessment by positron emission tomography. Circulation 1995;92:796-804.

13. Canetti M, Akther MW, Lerman A. IÜ̈̈Evaluation of myocardial blood flow reserve in patients with chronic congestive heart failure due to idiopathic dilated cardiomyopathy. Am J Cardiol 2003;92:1246-9.

14. Djordjevic Dikic A, Nikcevic G, Raspopovic S, Jovanovic V, Tesic M, Beleslin B, et al. Prognostic role of coronary flow reserve for left ventricular functional improvement after cardiac resynchronization therapy in patients with dilated cardiomyopathy. Eur Heart J Cardiovasc Imaging 2014;15:1344-9.

15. Duncker DJ, Bache RJ. Regulation of coronary blood flow during exercise. Physiol Rev 2008;88:1009-86.

16. Stolfo D, Ceschia N, Zecchin M, de Luca A, Gobbo M, Barbati G, et al. Arrhythmic risk stratification in patients with idiopathic dilated cardiomyopathy. Am J Cardiol 2018;121:1601-9.

17. Lionetti V, Matteucci M, Ribezzo M, Di Silvestre D, Brambilla F, Agostini $\mathrm{S}$, et al. Regional mapping of myocardial hibernation phenotype in idiopathic end-stage dilated cardiomyopathy. J Cell Mol Med 2014;18:396-414.

18. Gulati A, Ismail TF, Ali A, Hsu LY, Gonçalves C, Ismail NA, et al. Microvascular dysfunction in dilated cardiomyopathy: A quantitative stress perfusion cardiovascular magnetic resonance study. JACC Cardiovasc Imaging 2019;12:1699-708.

19. Prasad A, Higano ST, Al Suwaidi J, Holmes DR Jr., Mathew V, Pumper G, et al. Abnormal coronary microvascular endothelial function in humans with asymptomatic left ventricular dysfunction. Am Heart J 2003;146:549-54.

20. Neglia D, L'Abbate A. Coronary microvascular dysfunction and idiopathic dilated cardiomyopathy. Pharmacol Rep 2005;57 Suppl: 151-5.

21. Treasure CB, Vita JA, Cox DA, Fish RD, Gordon JB, Mudge GH, et al. Endothelium-dependent dilation of the coronary microvasculature is impaired in dilated cardiomyopathy. Circulation 1990;81:772-9.

22. Fenyo IM, Gafencu AV. The involvement of the monocytes/ macrophages in chronic inflammation associated with atherosclerosis. Immunobiology 2013;218:1376-84.

23. Sundell J, Engblom E, Koistinen J, Ylitalo A, Naum A, Stolen KQ, et al. The effects of cardiac resynchronization therapy on left ventricular function, myocardial energetics, and metabolic reserve in patients with dilated cardiomyopathy and heart failure. J Am Coll Cardiol 2004;43:1027-33.

24. Neri G, Zanco P, Zanon F, Buchberger R. Effect of biventricular pacing on metabolism and perfusion in patients affected by dilated cardiomyopathy and left bundle branch block: Evaluation by positron emission tomography. Europace 2003;5:111-5.

25. Nowak B, Sinha AM, Schaefer WM, Koch KC, Kaiser HJ, Hanrath P, et al. Cardiac resynchronization therapy homogenizes myocardial glucose metabolism and perfusion in dilated cardiomyopathy and left bundle branch block. J Am Coll Cardiol 2003;41:1523-8.

26. Lindner O, Vogt J, Kammeier A, Fricke E, Holzinger J, Lamp B, et al. Cardiac re-synchronization therapy: Effects on myocardial perfusion at rest, after vasodilation and oxygen consumption. Nuklearmedizin 2006;45:10-4.

27. Knaapen P, van Campen LM, de Cock CC, Götte MJ, Visser CA, Lammertsma AA, et al. Effects of cardiac resynchronization therapy on myocardial perfusion reserve. Circulation 2004;110:646-51.

28. Flevari P, Theodorakis G, Paraskevaidis I, Kolokathis F, Kostopoulou A, Leftheriotis D, et al. Coronary and peripheral blood flow changes following biventricular pacing and their relation to heart failure improvement. Europace 2006;8:44-50.

29. Blanc JJ, Fatemi M, Bertault V, Baraket F, Etienne Y. Evaluation of left bundle branch block as a reversible cause of non-ischaemic dilated cardiomyopathy with severe heart failure. A new concept of left ventricular dyssynchrony-induced cardiomyopathy. Europace 2005;7:604-10

30. Valzania C, Gadler F, Winter R, Braunschweig F, Brodin LA, Gudmundsson $\mathrm{P}$, et al. Effects of cardiac resynchronization therapy on coronary blood flow: Evaluation by transthoracic Doppler echocardiography. Eur J Heart Fail 2008;10:514-20.

31. Kaźmierczak J, Peregud-Pogorzelska M, Gorący J, Wojtarowicz A, Kiedrowicz R, Kornacewicz-Jach Z. Effect of cardiac resynchronisation therapy on coronary blood flow in patients with non-ischaemic dilated cardiomyopathy. Kardiol Pol 2014;72:511-8.

32. Yildirim A, Soylu O, Dagdeviren B, Ergelen M, Celik S, Zencirci E, et al. Cardiac resynchronization improves coronary blood flow. Tohoku J Exp Med 2007;211:43-7. 